\title{
Shuang-Huang-Lian prevents basophilic granulocyte activation to suppress Th2 immunity
}

\author{
Qiaoling Fei ${ }^{1}$, Yixin Han ${ }^{1}$, Ruijuan $\mathrm{Qi}^{1}$, Yuan Gao ${ }^{1}$, Lei Fang ${ }^{1}$, Rui Hou ${ }^{1}$, Runlan Cai ${ }^{1}$ and Yun $\mathrm{Qi}^{1,2^{*}}$ (D)
}

\begin{abstract}
Background: Basophilic granulocytes (BGs) not only initiate the induction of Th2 cell differentiation, but also amplify the ongoing Th2 response. Shuang-Huang-Lian (SHL) is clinically used for relieving type I hypersensitivity by continuous treatment for several weeks.

Methods: ELISA, flow cytometry, magnetic activated cell sorting, isoelectric precipitation, hybridoma technique, transfection and luciferase reporter assay were used in this study. The statistical analysis was performed using a one-way ANOVA.

Results: Our recently published study demonstrated that SHL exerted a remarkable effect on mast cell stabilization. Herein, we sought to elucidate the effect of SHL on shrimp tropomyosin (ST)-induced Th2 immunity and its underlying mechanisms. The obtained data showed that continuous treatment with SHL significantly suppressed ST-stimulated Th2-cytokines release and IgE synthesis. A mechanistic study indicated that SHL not only reduced BG early IL-4 release before ST-specific lgE (slgE) production, but also inhibited BG activation in the presence of slgE, including suppressing CD200R surface expression and decreasing IL-4 production. Moreover, SHL markedly decreased the cytosolic $\mathrm{Ca}^{2+}\left(\mathrm{Ca}_{[\mathrm{c}]}^{2+}\right)$ level and inhibited the nuclear factor of activated T cells (NFAT) activation in RBL-2H3 cells.

Conclusions: Collectively, SHL potently reduces ST-induced Th2 immunity by inhibiting the BG $\mathrm{Ca}^{2+}{ }^{2+N F A T}$ pathway and, thus, suppressing the early IL-4 release before slgE synthesis and inhibiting BG activation in the presence of slgE. This study provides the pharmacological basis for the clinical use of SHL to relieve type I hypersensitivity by a successive dose regimen.
\end{abstract}

Keywords: Basophilic granulocytes (BGs), Shuang-Huang-Lian (SHL), Th2 immunity, IL-4, NFAT, Cytosolic Ca ${ }^{2+}\left(\mathrm{Ca}_{[\mathrm{c}]}^{2+}\right)$

\section{Background}

Naïve CD4+ T (NCT) cells, also known as T-helper (Th) cells, play critical roles in orchestrating adaptive immune responses to a variety of pathogens. They are also involved in autoimmunity, asthma, and allergic responses as well as in tumor immunity. NCT cells produced in the thymus migrate to the periphery where they encounter antigens. In different cytokine milieus, NCT cells differentiate into distinct subsets of effector cells, which allow for tailored

\footnotetext{
* Correspondence: yqi@implad.ac.cn

'Institute of Medicinal Plant Development, Chinese Academy of Medical Sciences \& Peking Union Medical College, Beijing 100193, China

${ }^{2}$ Research Center for Pharmacology and Toxicology, Institute of Medicinal Plant Development, Chinese Academy of Medical Science and Peking Union Medical College, 151 North Ma Lian Wa Road, Haidian District, Beijing,

People's Republic of China
}

immune responses against specific antigens. Th1 and Th2 cells are two major CD4 + effector T-cell subsets [1]. The Th1 cell immune response is characterized by the production of cytokines (e.g., IFN- $\gamma$ ), and the enhanced productions of $\operatorname{IgG}_{2 \mathrm{a}}$ and $\mathrm{IgG}_{2 \mathrm{~b}}$ in mice. The Th2 response is characterized by the predominant production of IL-4, IL-5, IL-10, and immunoglobulins, mainly IgE $[2,3]$. In addition to suppressing type 1 immunity and type 1-driven inflammation, type 2 immunity is a major effector response that has many important host-protective and pathogenic activities. One of the most important protective functions of type 2 immunity for host defense is to promote resistance to large extracellular helminth parasites, but it is detrimental in allergic diseases in humans 
[4]. Thus, the suppression of type 2 responses is a useful therapeutic strategy for the treatment of allergic diseases.

Unlike Th1 immunity, in which dendritic cells (DCs) present antigens and produce Th1-inducing cytokines, such as IFN- $\gamma$ (and, in humans, also by type I IFN [5]), DCs fail to produce IL-4, the key driver of CD4+ Th2 cell responses. Therefore, the induction of Th2 responses may require an alternative (non-DC) antigen-presenting cell (APC). Under homeostatic conditions, mature basophilic granulocytes (BGs) are found circulating in the peripheral blood as well as in highly vascularized organs. However, upon immunological stimulation, the activated BGs rapidly migrate into draining lymph nodes (LNs) from the site of antigen injection or helminth infection and act as APCs by uptaking and processing antigens [6-10]. Indeed, many studies have suggested that BG-derived IL-4 is crucial for promoting Th2 skewing upon cysteine proteases, allergens and extracellular parasites [9, 11], and thus, BGs trump DCs as APCs for Th2 responses [12].

Shuang-Huang-Lian (SHL), a formula containing Lonicerae Japonicae Flos, Scutellaria baicalensis and Fructus Forsythiae, is consistently prepared by a stringent manufacturing procedure from Chinese Pharmacopoeia [13]. Clinically, SHL products are generally considered antimicrobial agents and are delivered through different routes (e.g., oral, intravenous and pulmonary routes, etc.) [13]. Our previous studies showed that SHL protects lung tissue from infections via its potential anti-inflammatory and anti-oxidative activities [14, 15]. Moreover, our more recent study revealed that a single intraperitoneal treatment of an SHL injection potently dampens compound 48/80-MrgprX2 and IgE-FceRI mediated mast cell (MC) degranulation [16]. Nevertheless, SHL is commonly used for relieving type I hypersensitivity by a continuous treatment for several weeks $[17,18]$, suggesting that the function of SHL might not only be attributed to short-term MC stabilization, but also involve a long-term therapeutic effect. Thus, the present study focused on the effect of SHL on shrimp tropomyosin (ST)-induced Th2 immunity and its underlying mechanisms.

\section{Methods \\ Materials}

The SHL injection, prepared according to the Chinese Pharmacopoeia [13], was provided by Duoduo Pharmaceutical Co., Ltd. (Jiamusi, Heilongjiang, China). Pluonic F-127 and active papain were from Sigma-Aldrich (St Louis, MO, USA). Fluo-3 AM Ester was from Biotium (San Francisco, CA, USA). Mouse total IgE (tIgE), IL-4, IL-5 and IL-10 ELISA kits were from Biolegend Co. (San Diego, CA, USA). Mouse IL-13 and IFN- $\gamma$ ELISA kits were from Excell Bio. Co. (Shanghai, China). Recombinant mouse IL-3 was from Novoprotein (Summit, NJ, USA).
Mouse direct lineage cell depletion kit, CD3-FITC antibody, CD117-APC antibody, CD19-VioBright (TM) FITC antibody, CD117 Microbeads, FceRI-PE antibody, anti-PE Microbeads and Red Blood Cell Lysis solution were from Miltenyi Biotec Inc. (Auburn, CA, USA). Protein G PLUS-Agarose was from Santa Cruz Biotechnology, Inc. (Santa Cruz, CA, USA). The HRP-labeled rat antimouse IgE antibody and HRP-labeled goat anti-rabbit antibody were from Abcam Co. (Cambridge, UK) and Jackson ImmunoResearch Laboratories Inc. (Lancaster, PA, USA), respectively. The rabbit anti-mouse $\operatorname{IgG}_{2 \mathrm{a}}$ and $\operatorname{IgG}_{2 \mathrm{~b}}$ antibodies were from OriGene Technologies, Inc. (Rockville, MD, USA). The nuclear factor of activated $\mathrm{T}$ cells (NFAT)-luc plasmid and its control were synthesized by GenePharma Co., Ltd. (Shanghai, China). The FITClabeled anti-mouse IgE antibody and PE-labeled antimouse CD200R antibody were from BD Biosciences (Franklin Lakes, NJ, USA) and eBioscience (San Diego, CA, USA), respectively. The luciferase assay system was from Beyotime Institute of Biotechnology (Haimen, Jiangsu, China). Imject alum adjuvant was from Thermo Fisher Scientific (New York, NY, USA). The other reagents were of analytical grade.

\section{Cell line and animals}

The rat basophilic leukemia cell line (RBL-2H3) was obtained from the cell bank of the Chinese Academy of Sciences (Shanghai, China). The Balb/c mice (male, 18-20 g) were from Vital River Experimental Animal Services (Beijing, China) and housed in a SPF laboratory in standard temperature and humidity conditions with a $12 \mathrm{~h}$ light/dark cycle. They were randomly divided into 4 groups (8 mice per group): normal saline group (NS), ST model group and SHL groups (3 and $6 \mathrm{~mL} / \mathrm{kg}$ ). All the animal experiments were carried out according to the National Institutes of Health Guide for Care and Use of Laboratory Animals and approved by the Institutional Animal Care and Use Committee (IACUC), Institute of Medicinal Plant Development (IMPLAD) of Chinese Academy of Medical Sciences (Licence nos. 20160314, 20160426, 20160505). Anesthetic drugs and all other necessary measures were used to reduce animal suffering during experimental procedures.

\section{Isolation of ST and production of ST-specific $\lg \mathrm{E}$ (slgE) monoclonal antibody (mAb)}

ST and ST-sIgE mAb were prepared as we previously described [14].

\section{Sensitization protocol}

ST-sensitized mice were prepared as shown in Additional file 1: Figure S1. Mice were injected (i.p.) weekly (days 0, 7, 14 and 21) with imject alum 
containing ST (60 $\mu \mathrm{g} / \mathrm{mouse})$. Simultaneously, the mice were treated daily with SHL (3 mL/kg or $6 \mathrm{~mL} / \mathrm{kg}$, i.g.) or physiologic saline (normal control group and ST model group). 4 weeks later (day 28), the mice were anesthetized by inhalation of diethyl ether and euthanized by cervical dislocation. The blood, sera and spleens were collected for the experiments.

\section{Measurement of serum tlgE and ST-specific antibodies}

Th1 cells regulate $B$ cells to produce antigen-specific $\operatorname{IgG}_{2 \mathrm{a}}$ and $\operatorname{IgG}_{2 \mathrm{~b}}$, while Th2 cells induce an allergic inflammation by promoting IgE class switching $[2,3]$. To clarify the function of SHL on the Th1/Th2 phenotype, we evaluated the effect of SHL on ST-specific serum antibody production. The serum tIgE level was measured using a commercial mouse tIgE ELISA kit. The levels of sIgE were measured as previously described with some modifications [19]. Briefly, IgG in the serum was removed by Protein G PLUS-Agarose according to the manufacturer's instructions. The 96-well microtiter plates were coated with ST $(10 \mu \mathrm{g} / \mathrm{mL}, 100 \mu \mathrm{L} /$ well $)$ in coating buffer (0.05 M carbonate buffer, $\mathrm{pH}$ 9.6). After an overnight incubation at $4{ }^{\circ} \mathrm{C}$, the plates were washed 4 times with $\mathrm{PBS} / 0.05 \%$ Tween 20 and were blocked with $1 \%$ BSA-PBS at $37{ }^{\circ} \mathrm{C}$ for $1 \mathrm{~h}$. After washing, the serum samples (1:100 dilutions) were added to the plates and were incubated overnight at $4{ }^{\circ} \mathrm{C}$. After washing, $100 \mu \mathrm{L}$ of the HRP-labeled rat anti-mouse IgE antibody (1:5000 dilutions) was added. The plates were incubated at $37{ }^{\circ} \mathrm{C}$ for $1 \mathrm{~h}$. The reactions were developed with TMB for $5 \mathrm{~min}$ at $37^{\circ} \mathrm{C}$ and were stopped by $100 \mu \mathrm{L}$ of $2 \mathrm{M} \mathrm{H}_{2} \mathrm{SO}_{4}$. The optical density (OD) was read at $450 \mathrm{~nm}$.

For measuring the ST-specific IgG (sIgG) in the serum, the serum samples (1:100 dilutions) were added in the plate coated with ST $(10 \mu \mathrm{g} / \mathrm{mL})$ followed by an incubation at $37^{\circ} \mathrm{C}$ for $1 \mathrm{~h}$. After washing, $100 \mu \mathrm{L}$ of the rabbit anti-mouse $\operatorname{IgG}_{2 \mathrm{a}}$ or $\operatorname{IgG}_{2 \mathrm{~b}}$ antibody was added. After a further incubation at $37^{\circ} \mathrm{C}$ for $1 \mathrm{~h}$ and washing, $100 \mu \mathrm{L}$ of the HRP-labeled goat anti-rabbit antibody (1:5000 dilutions) was added, and the plate was incubated at $37{ }^{\circ} \mathrm{C}$ for $1 \mathrm{~h}$. The reactions were developed with TMB for $10 \mathrm{~min}$ at $37{ }^{\circ} \mathrm{C}$ and were terminated by $100 \mu \mathrm{L}$ of $2 \mathrm{M} \mathrm{H}_{2} \mathrm{SO}_{4}$. The $\mathrm{OD}$ values were read at $450 \mathrm{~nm}$. The serum ST-specific antibody levels were calculated by comparing the OD values.

\section{Splenocyte culture and cytokine measurement}

In contrast to Th1 cells, which produce IFN- $\gamma$, Th2 cells produce cytokines, such as IL-4, IL-5, IL-10 and IL-13, which are important in switching antibody production from B cells to predominantly IgE synthesis against the allergen [20]. Thus, the effect of SHL on cytokine production in the splenocytes was assayed. Spleens from the ST-sensitized mice were taken and single cell suspensions were prepared aseptically in DMEM according to a previously described method [21]. The obtained splenocytes $\left(4 \times 10^{6}\right.$ cells/well $)$ were seeded in a 24 -well plate and challenged by ST $(8 \mu \mathrm{g} / \mathrm{mL})$ at $37{ }^{\circ} \mathrm{C}$ for $72 \mathrm{~h}$. The levels of IL-4, IL-5, IL-10, IL-13 and IFN- $\gamma$ in the culture medium were measured using respective ELISA kits according to the manufacturer's instructions.

\section{Measurement of cytosolic $\mathrm{Ca}^{2+}\left(\mathrm{Ca}_{[\mathrm{c}]}^{2+}\right)$ level}

The $\mathrm{Ca}_{[\mathrm{c}]}^{2+}$ level in the $\mathrm{RBL}-2 \mathrm{H} 3$ cells was determined using the calcium-reactive fluorescence probe Fluo-3/ AM as we previously described [16].

\section{BG activation test}

Measurement of the IL-4 level produced by BG-rich splenocytes and sensitized RBL-2H3 cells

By producing Th2-promoting cytokines (e.g. IL-4), BGs promote Th2 skewing in response to various antigens in the absence/presence of DCs [7]. Thus, the effect of SHL on early IL-4 production in BG-rich splenocytes in response to papain or ST was investigated. BG-rich splenocytes were prepared as previously described with some modifications [10]. T cells, B cells and mast cells in spleen were depleted by a Direct Lineage Cell Depletion kit and CD117 Microbeads via a MACS (Miltenyi Biotec) negative selection $\left(\mathrm{CD} 3^{-} \mathrm{CD} 19^{-} \mathrm{CD} 117^{-}\right)$and were then enriched via a MACS positive selection $\left(\mathrm{FcERI}^{+}\right)$. Briefly, the Balb/c mice $(n=20)$ were anesthetized and sacrificed by cervical dislocation. The spleens were sterilely removed and dissociated by cell strainer to obtain single-cell suspension. The red blood cells from the spleen cell samples from the mice were removed by the Red Blood Cell Lysis solution. Next, $100 \mu \mathrm{L}$ of Direct Lineage Cell Depletion Cocktail and $200 \mu \mathrm{L}$ of CD117 Microbeads were added into the obtained cells $\left(1 \times 10^{8}\right.$ cells). Mix well and incubate for $15 \mathrm{~min}$ at $4{ }^{\circ} \mathrm{C} .6 \mathrm{~mL}$ of medium was added and the cell suspension was centrifuged at $300 \times \mathrm{g}$ for $10 \mathrm{~min}$ at $4{ }^{\circ} \mathrm{C}$. Aspirate supernatant completely and resuspend the cells by $1 \mathrm{~mL}$ medium. Prepare the LS column by rinsing with $3 \mathrm{~mL}$ of the medium and apply the cell suspension onto the column. Collect the unlabeled cell suspension that pass through and combine with the flow-through and centrifuge at $300 \times \mathrm{g}$ for $10 \mathrm{~min}$ at $4{ }^{\circ} \mathrm{C}$. The obtained cells were stained by $10 \mu \mathrm{L}$ of anti-FceRI $\alpha$-PE antibody and $100 \mu \mathrm{L}$ of anti-PE Microbeads for $15 \mathrm{~min}$ at $4{ }^{\circ} \mathrm{C}$ and centrifuged to aspirate supernatant. Apply the cell suspension onto the column and wash column with the $10 \mathrm{~mL}$ of medium. Pipette $3 \mathrm{~mL}$ of medium onto the column and immediately flush out the magnetically labeled cells $\left(\mathrm{Fc}_{\mathrm{C} R \mathrm{RI}^{+}}\right)$by firmly pushing the plunger into the column. Collect the obtained cell suspension $\left(\mathrm{FccRI}^{+}\right)$. The 
purity of the BGs in the obtained cells was analyzed by using a FACSCalibur flow cytometer and the value was 13.66\% (see Additional file 2: Figure S2). The obtained BG-rich splenocytes $\left(1 \times 10^{6}\right.$ cells/well $)$ were seeded in a 96-well plate and treated with SHL (0.5-2\%) and ST $(100 \mu \mathrm{g} / \mathrm{mL})$ or active papain $(100 \mu \mathrm{g} / \mathrm{mL})$ in the presence of IL-3 $(1 \mu \mathrm{g} / \mathrm{mL})$ for $24 \mathrm{~h}$. The supernatants were analyzed for IL-4 levels by ELISA.

To determine the effect of SHL on the BGs after sIgE synthesis, the RBL-2H3 cells were sensitized with anti-ST IgE $(25 \mu \mathrm{g} / \mathrm{mL})$ at $37{ }^{\circ} \mathrm{C}$ overnight. The cells were pretreated with or without SHL $(0.5-2 \%)$ at $37{ }^{\circ} \mathrm{C}$ for $30 \mathrm{~min}$ and were then stimulated with ST $(20 \mathrm{ng} / \mathrm{mL})$ for $6 \mathrm{~h}$. IL4 levels in the supernatants were assayed by ELISA.

\section{Measurement of the peripheral BG activation marker CD200R}

BGs bind IgE through high affinity receptors (FceRI) on their surface. Upon antigen stimulation, the activated BGs rapidly migrate into draining $\mathrm{LNs}$ and release a great amount of IL-4 to amplify Th2 responses [6,9]. Thus, we determined the effect of SHL on CD200R surface expression, a marker of murine BG activation [22], in peripheral BGs from the ST-sensitized mice and IL-4 release in the anti-ST IgE-sensitized RBL-2H3 cells. For the CD200R assay, the whole blood from the ST-sensitized mice was collected in EDTA- $\mathrm{K}_{2}$ anticoagulative tube $(100 \mu \mathrm{L} /$ tube $)$ and was incubated with ST at $5 \mu \mathrm{g} /$ $\mathrm{mL}$ for $2 \mathrm{~h}$ at $37^{\circ} \mathrm{C}$. The cells were stained with a FITClabeled anti-mouse IgE antibody and a PE-labeled antimouse CD200R antibody for $15 \mathrm{~min}$ at $25^{\circ} \mathrm{C}$. The erythrocytes were lysed, and the leukocytes were fixed using a whole blood lysing reagent kit for $5 \mathrm{~min}$ at room temperature. The cells were washed in $2 \mathrm{~mL}$ of PBS and resuspended in $300 \mu \mathrm{L}$ of PBS for an analysis using a FACSCalibur flow cytometer [22].

\section{Plasmids, transfection and luciferase reporter assay}

Given that the transcription of IL-4 is regulated by NFAT [23], we determined the effect of SHL on NFAT activation in the RBL-2H3 cells stably transfected with the pNFAT-luc plasmid. The RBL-2H3 cells were transfected with pNFAT-luc and its control plasmids by electroporation. Stable cells were obtained by G418 (400 $\mu \mathrm{g} /$ $\mathrm{mL}$ ) selection. For the NFAT assay, the cells were sensitized by anti-ST IgE $(25 \mu \mathrm{g} / \mathrm{mL})$ overnight and were then
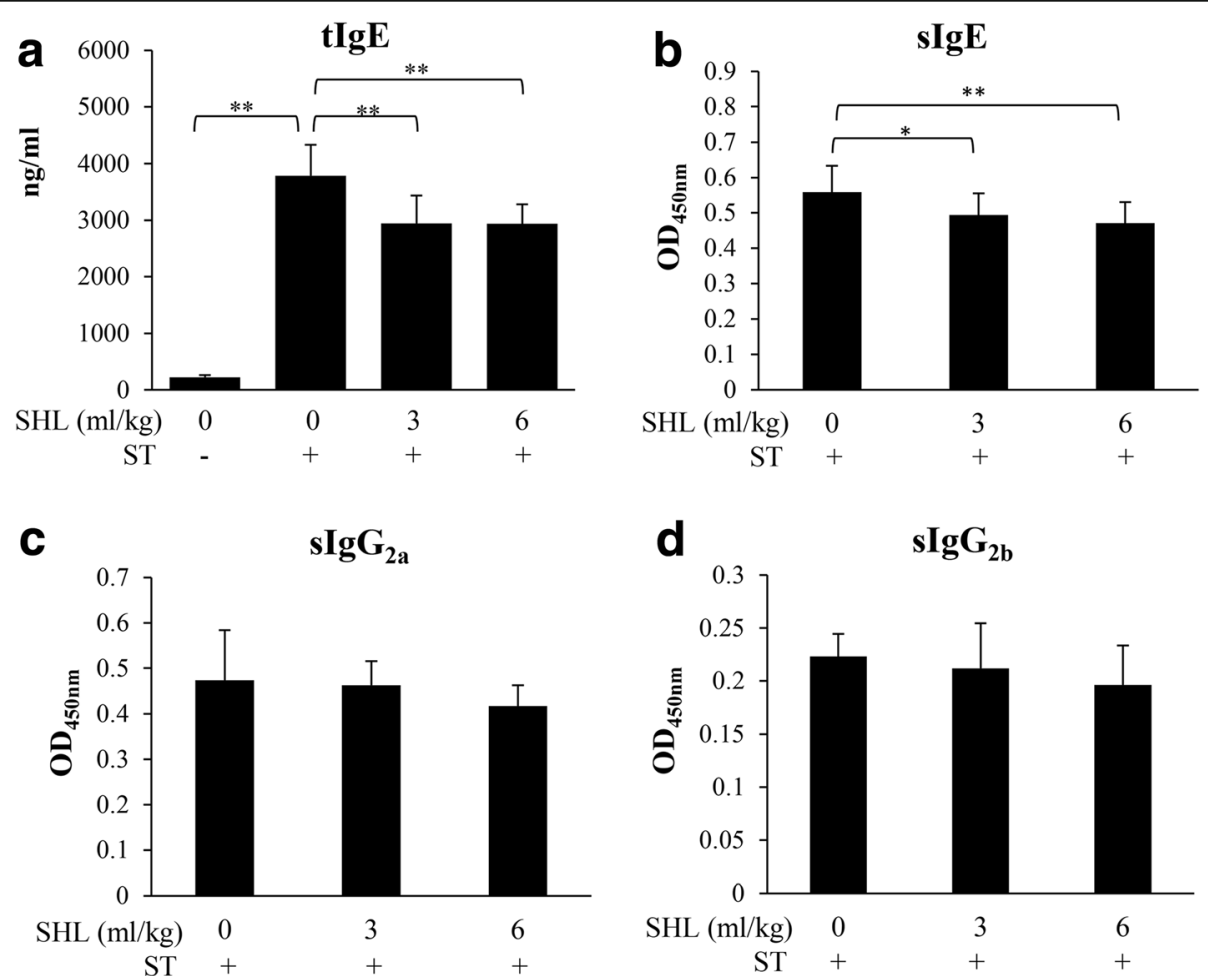

Fig. 1 Effects of SHL on the serum tlgE (a), slgE (b), slgG $G_{2 a}(\mathbf{c})$ and $\operatorname{slgG}_{2 b}(\mathbf{d})$ productions in the ST-sensitized mice. Mice were intraperitoneally immunized with ST ( $60 \mu \mathrm{g} / \mathrm{mouse}$ ) once a week. SHL (3 mL/kg or $6 \mathrm{~mL} / \mathrm{kg}$, i.g.) was daily administrated daily to the mice. 4 weeks later the mice were sacrificed and the sera were collected. The serum tlgE was determined by a commercial ELISA kit. The slgE, slgG $\mathrm{G}_{2 a}$ and slgG $\mathrm{G}_{2 \mathrm{~b}}$ levels were assayed by our established ELISA. The data represent the means \pm SD $(n=10)$. ${ }^{*} P<0.05$ and ${ }^{* *} P<0.01$ 
pre-incubated with different concentrations of SHL, and $0.5 \mathrm{~h}$ later, the cells were stimulated by ST $(20 \mathrm{ng} / \mathrm{mL})$ for $6 \mathrm{~h}$. The cells were lysed, and the luciferase activity was measured using the luciferase assay system.

\section{Statistical analysis}

The data represent the mean \pm SD of at least three independent experiments. The statistical analysis was performed using a one-way ANOVA. A student's $t$ test was used when only two groups were compared. The difference was considered statistically significant when $P<0.05$.

\section{Results}

SHL decreases serum tlgE and slgE levels in ST-sensitized mice

As shown in Fig. 1, ST induced $\operatorname{sgE}, \operatorname{sIg} G_{2 \mathrm{a}}$ and $\operatorname{sg} G_{2 \mathrm{~b}}$ production after 4 weeks of ST immunization, while SHL significantly reduced serum tIgE and sIgE levels (Fig. 1a-b and Additional file 3: Table S1) but did not affect $\operatorname{sIgG}_{2 \mathrm{a}}$ and $\operatorname{sIgG}_{2 \mathrm{~b}}$ (Fig. 1c-d and Additional file 3: Table S1), indicating the suppressive effect of SHL on the ST-induced Th2 immunity.
SHL suppresses Th2 cytokine production by splenocytes from the ST-sensitized mice

As shown in Fig. 2, in vitro ST stimulation significantly increased the release of IL-4, IL-5, IL-10 and IL-13 but simultaneously decreased IFN- $\gamma$ secretion. A continuous treatment with SHL (i.g.) significantly reduced STinduced IL-4, IL-5, IL-10 and IL-13 productions (Fig. 2a-d and Additional file 4: Table S2) but did not affect IFN- $\gamma$ release (Fig. 2e and Additional file 4: Table S2), indicating that SHL suppressed ST-induced Th2 immunity. Furthermore, splenocytes from the unsensitized normal mice showed no response to an ST challenge (data not shown).

\section{SHL suppresses BG activation}

$S H L$ decreases IL-4 release in BG-rich splenocytes upon papain or ST stimulus

As shown in Fig. 3a and Additional file 5: Table S3, papain markedly stimulated BG-rich splenocytes to release large amounts of IL-4. Intriguingly, ST also dramatically elevated IL-4 release. Whether papain or ST challenge, SHL potently reduced $\mathrm{IL}-4$ production in a

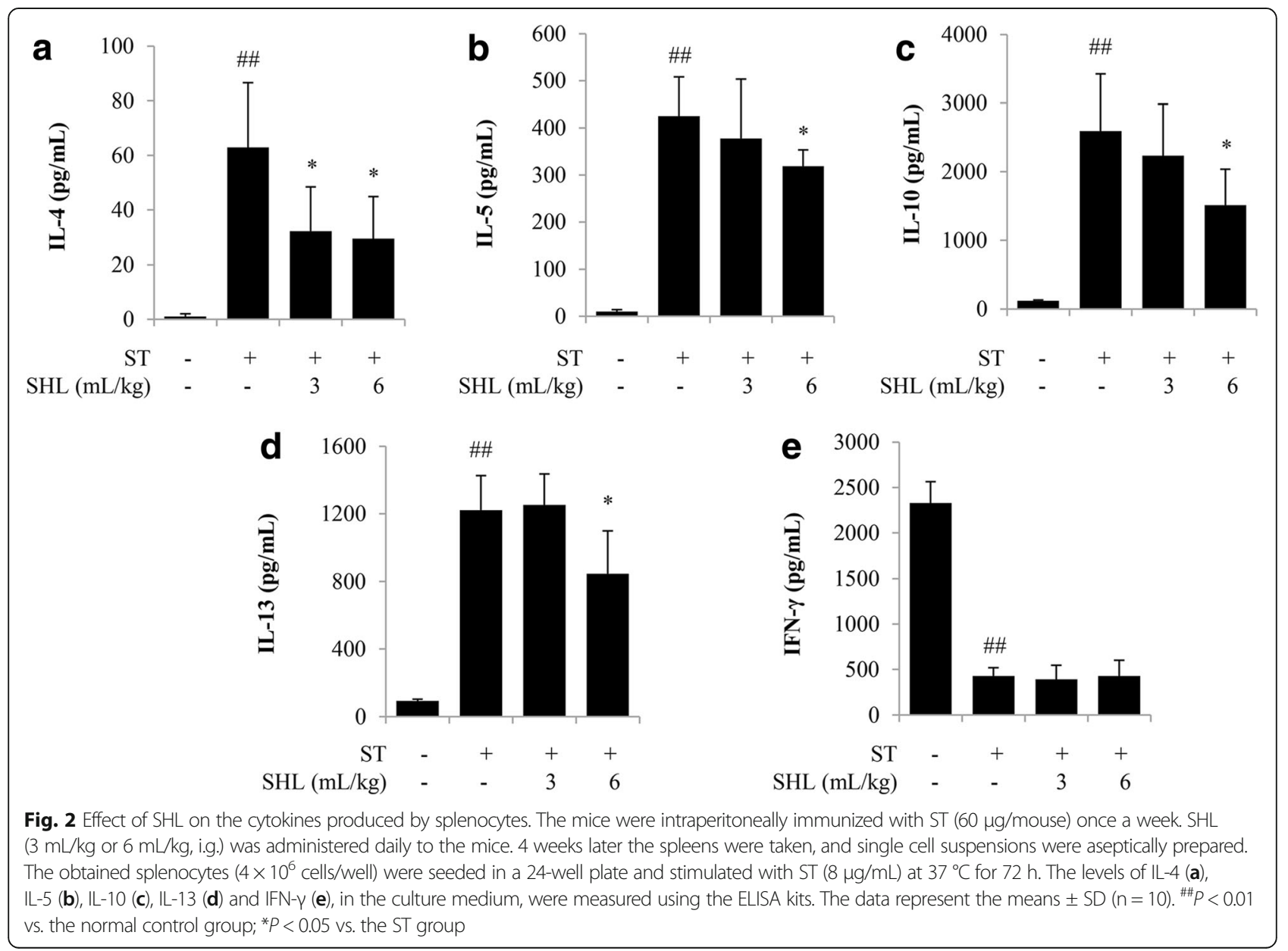


a

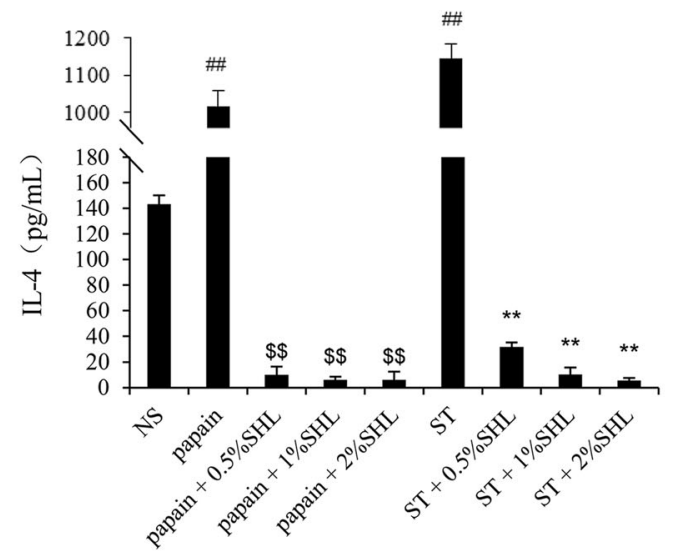

b
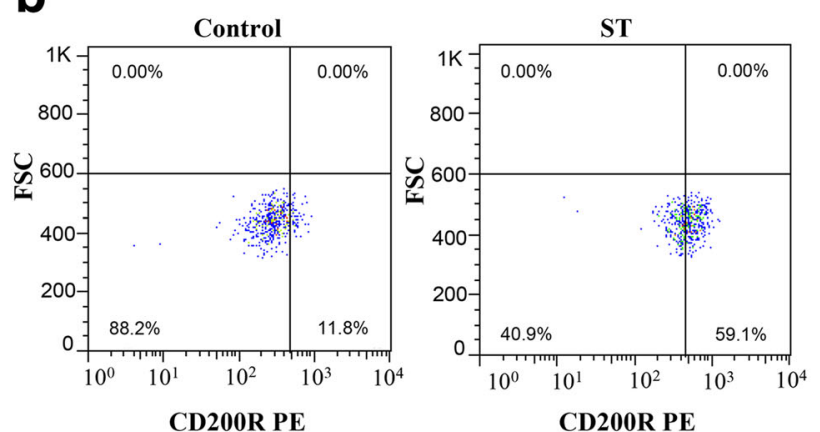

CD200R PE
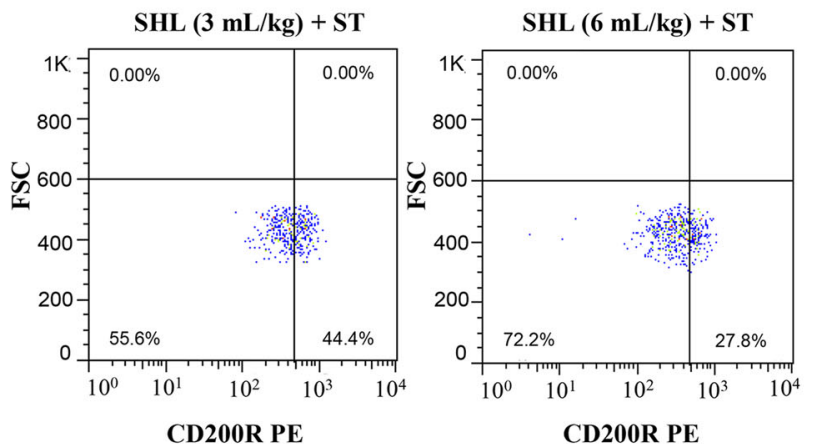

C

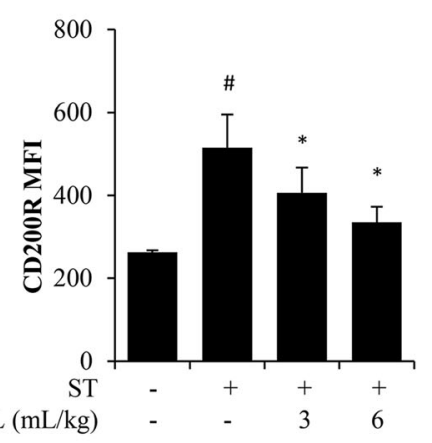

d

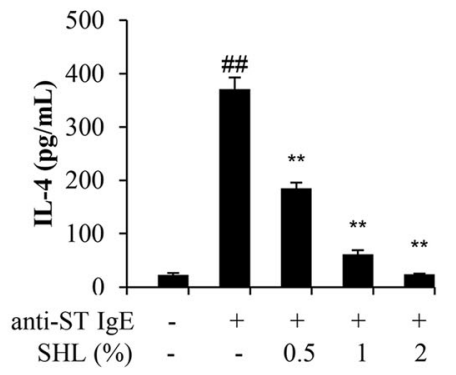

e

NFAT

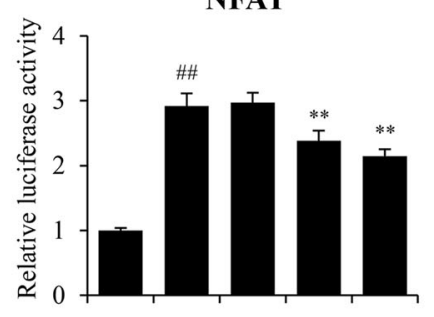

$\begin{array}{rlllll}\mathrm{ST}(20 \mathrm{ng} / \mathrm{mL}) & - & + & + & + & + \\ \mathrm{SHL}(\%) & - & - & 0.5 & 1 & 2\end{array}$

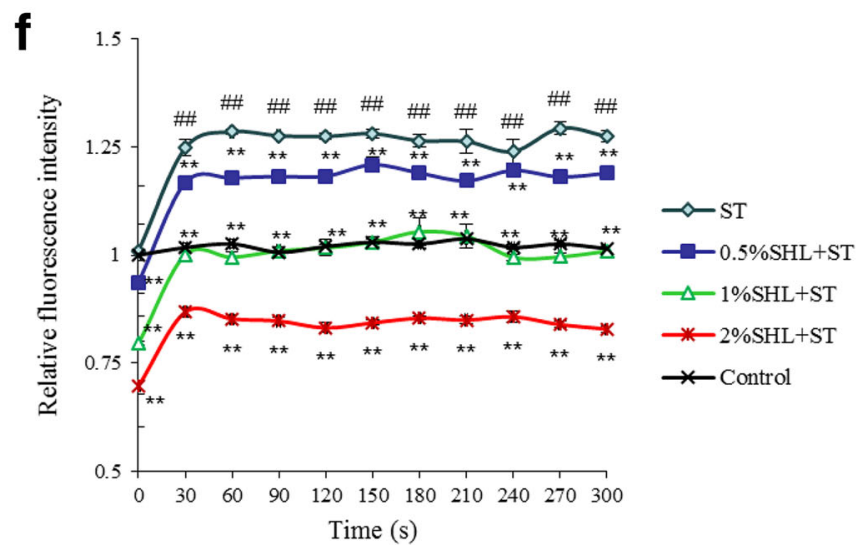

Fig. 3 (See legend on next page.) 
(See figure on previous page.)

Fig. 3 a SHL decreased early IL-4 produced by BG-rich splenocytes. Splenic BGs, preliminarily purified by a MACS system, were seeded in a 96-well plate $\left(1 \times 10^{6}\right.$ cells/well) and treated with SHL $(0.5-2 \%)$ and ST $(100 \mu \mathrm{g} / \mathrm{mL})$ or active papain $(100 \mu \mathrm{g} / \mathrm{mL})$ in the presence of IL-3 $(1 \mu \mathrm{g} / \mathrm{mL})$ for $24 \mathrm{~h}$. IL-4 levels in the supernatants were analyzed by ELISA. ${ }^{\# \#} P<0.01$ vs. NS; ${ }^{\$ \$} P<0.01$ vs. papain alone; ${ }^{* *} P<0.01$ vs. ST alone. b-c SHL inhibited BG CD200R surface expression. The whole blood from the ST-sensitized mice was collected and stained with anti-lgE FITC and anti-CD200R antibodies after an incubation with ST $(5 \mu \mathrm{g} / \mathrm{mL})$ for $2 \mathrm{~h}$ at $37^{\circ} \mathrm{C}$. BGs in the whole blood were identified by an anti-lgE FITC antibody. The surface expression of CD200R on the BGs was assayed by flow cytometry. Isotype control and unstained cells were used as the negative controls. b Representative dot plots of BG CD200R surface expression. c Effect of SHL on the mean fluorescence intensity (MFI) of CD200R in the BGs after stimulation with ST. d SHL decreased IL-4 release in the sensitized RBL-2H3 cells. The cells were sensitized with anti-ST IgE $(25 \mu \mathrm{g} / \mathrm{mL})$ at $37{ }^{\circ} \mathrm{C}$ overnight. The cells were pretreated with or without SHL at $37^{\circ} \mathrm{C}$ for 30 min and were then stimulated with ST (20 ng/mL) for $6 \mathrm{~h}$. IL-4 levels in the supernatants were assayed using a commercial ELISA kit. e SHL suppressed ST-induced NFAT activation in BGs. RBL-2H3 cells stably transfected with the pNFAT-luc plasmid were sensitized with anti-ST IgE $(25 \mathrm{\mu g} / \mathrm{mL})$ at $37^{\circ} \mathrm{C}$ overnight. The cells were pretreated with or without SHL at $37^{\circ} \mathrm{C}$ for 30 min and were then stimulated with ST $(20 \mathrm{ng} / \mathrm{mL})$ for $6 \mathrm{~h}$. The cells were lysed and the luciferase activity was measured using the luciferase assay system. $\mathbf{f}$ SHL reduced Ca $\mathrm{Ca}_{[\mathrm{C}}^{2+}$ levels in the RBL-2H3 cells. The RBL-2H3 cells were sensitized with anti-ST IgE $(25 \mu \mathrm{g} / \mathrm{mL})$ at $37^{\circ} \mathrm{C}$ overnight. The cells were loaded with Fluo-3 AM (4 $\left.\mu \mathrm{M}\right)$ at $30^{\circ} \mathrm{C}$ for $30 \mathrm{~min}$. The stained cells were treated with or without SHL for $30 \mathrm{~min}$ and were then exposed to ST (20 ng/mL). The fluorescent intensity $\left(\lambda_{\text {ex }}\right.$ $485 \mathrm{~nm}$ and $\lambda_{\mathrm{em}} 538 \mathrm{~nm}$ ) was recorded every $30 \mathrm{~s}^{\#}{ }^{\#} P<0.05$ and ${ }^{\# \#} P<0.01$ vs. the control; ${ }^{*} P<0.05,{ }^{* *} P<0.01$ vs. ST alone

concentration-dependent manner without cytotoxicity (see Additional file 6: Figure S3).

\section{SHL suppresses CD200R surface expression in peripheric BGs and IL-4 production in anti-ST IgE-sensitized RBL-2H3 cells}

The obtained results (Fig. $3 \mathrm{~b}-\mathrm{c}$ and Additional file 5: Table S3) showed that in vitro ST stimulation resulted in a considerable increase in the percentage of CD200R surface expression (positive percentage $=59.1 \%$ ) compared with that of the normal control group (positive percentage $=11.8 \%$ ). Similarly, the mean fluorescence intensity (MFI) of the CD200R PE staining in the BG population also increased after ST application. However, SHL significantly suppressed BG CD200R surface expression with positive percentages of $44.4 \%(3 \mathrm{~mL} / \mathrm{kg})$ and $27.8 \%(6 \mathrm{~mL} / \mathrm{kg})$ and lower MFI values. In addition, an anti-FceRI antibody only may bind to FceRI that is not occupied by IgE. As a result, the antibody was not able to label the peripheral BGs in the ST-sensitized mice with high-level serum IgE. Hence, we used an antiIgE antibody instead (Fig. 3b-c). Moreover, SHL potently decreased ST-induced IL-4 elevation concentrationdependently in the sensitized RBL-2H3 cells (Fig. 3d and Additional file 5: Table S3) without cytotoxicity [16].

\section{SHL decreases $\mathrm{Ca}_{[\mathrm{c}]}^{2+}$ levels and inhibits NFAT activation in the sensitized RBL-2H3 cells}

As shown in Fig. 3e and Additional file 5: Table S3, SHL suppressed ST-stimulated NFAT activation in a concentration-dependent manner. NFAT are a family of $\mathrm{Ca}^{2+}$-dependent transcription factors [23]. Thus, we next investigated whether SHL inhibited the ST-induced $\mathrm{Ca}_{[\mathrm{c}]}^{2+}$ elevation in RBL-2H3 cells. As expected, ST challenge markedly elevated $\mathrm{Ca}_{[\mathrm{c}]}^{2+}$ levels in the sensitized $\mathrm{RBL}-2 \mathrm{H} 3$ cells, while a pretreatment with SHL significantly reduced $\mathrm{Ca}_{[\mathrm{c}]}^{2+}$ levels in a concentration-dependent manner (Fig. 3f and Additional file 5: Table S3), demonstrating that SHL suppressed ST-induced Th2 immunity via the regulation of the $\mathrm{Ca}^{2+}$-NFAT pathway.

\section{Discussion}

As a traditional Chinese formula, SHL is not only used for the treatment of acute upper respiratory tract infection, acute bronchitis and light pneumonia caused by bacterium/viruses, but also applied to treat IgE-mediated allergy, such as bronchial asthma [17, 18], etc. Previous studies have showed that all of the components in SHL possess the anti-allergic activity [24-26], of which the effect of Scutellaria baicalensis on Th2 immunity has been identified [27], highly suggesting that SHL is also likely to suppress Th2 immunity.

Th cells play an important role in orchestrating adaptive immune responses. Th2 immunity controls the humoral immune response by triggering B cell differentiation and producing IgE via Th2 cytokines [28]. ST, a more sensitive antigen to rodents than ovalbumin [16], was used in our study. 4 weeks after ST immunization, the mice showed Th2-bias response. SHL significantly decreased ST-stimulated splenocyte Th2-cytokines (IL-4, IL-5, IL-10 and IL-13) production (Fig. 2a-d and Additional file 4: Table S2) without affecting Th1 cytokine IFN- $\gamma$ (Fig. 2e and Additional file 4: Table S2). Simultaneously, ST-elevated serum tIgE and sIgE levels were also lowered by SHL (Fig. 1a-b and Additional file 3: Table S1), indicating that SHL indeed suppressed Th2 immunity.

In spite of representing less than $1 \%$ of peripheral blood leukocytes, BGs have become increasingly recognized as important innate immune cells [29]. On the one hand, BGs, as the effectors, are the main contributor to IgG-mediated anaphylaxis working through the release of platelet-activating factor, a highly potent proinflammatory phospholipid [30]. On the other hand, the activated BGs migrate into draining LNs and act as APCs by taking up and processing antigens. By releasing IL-4, BGs induces Th2 skewing upon peptide and hapten 
exposure [8-10], and they also promote Th2 polarization upon protein antigen exposure in the presence of DCs [7]. Even when the antigen-specific IgE appears, BGs that migrate into the LNs can still amplify the ongoing Th2 response by releasing IL-4 in greater amounts [10]. Our data showed that SHL suppressed BG activation marker expression (Fig. 3b-c and Additional file 5: Table S3). Moreover, SHL concentration-dependently decreased BG IL-4 production in the absence/presence of sIgE (Fig. 3a and d, and Additional file 5: Table S3), demonstrating that SHL inhibited BG activation.

The transcription of $\mathrm{IL}-4$ is regulated by $\mathrm{Ca}^{2}$ ${ }^{+}$-dependent transcription factors NFAT. A rise in $\mathrm{Ca}_{[\mathrm{c}]}^{2+}$ catalyzes the dephosphorylation of NFAT, and dephosphorylated NFAT translocates to the nucleus and subsequently initiating the transcription of IL-4 [23]. SHL significantly inhibited ST-stimulated NFAT activation in a concentration-dependent manner (Fig. $3 e$ and Additional file 5: Table S3). Based on our recent finding that SHL rapidly decreases $\mathrm{Ca}_{[\mathrm{c}]}^{2+}$ levels by activating mitochondrial calcium uniporter [16], we presumed that SHL

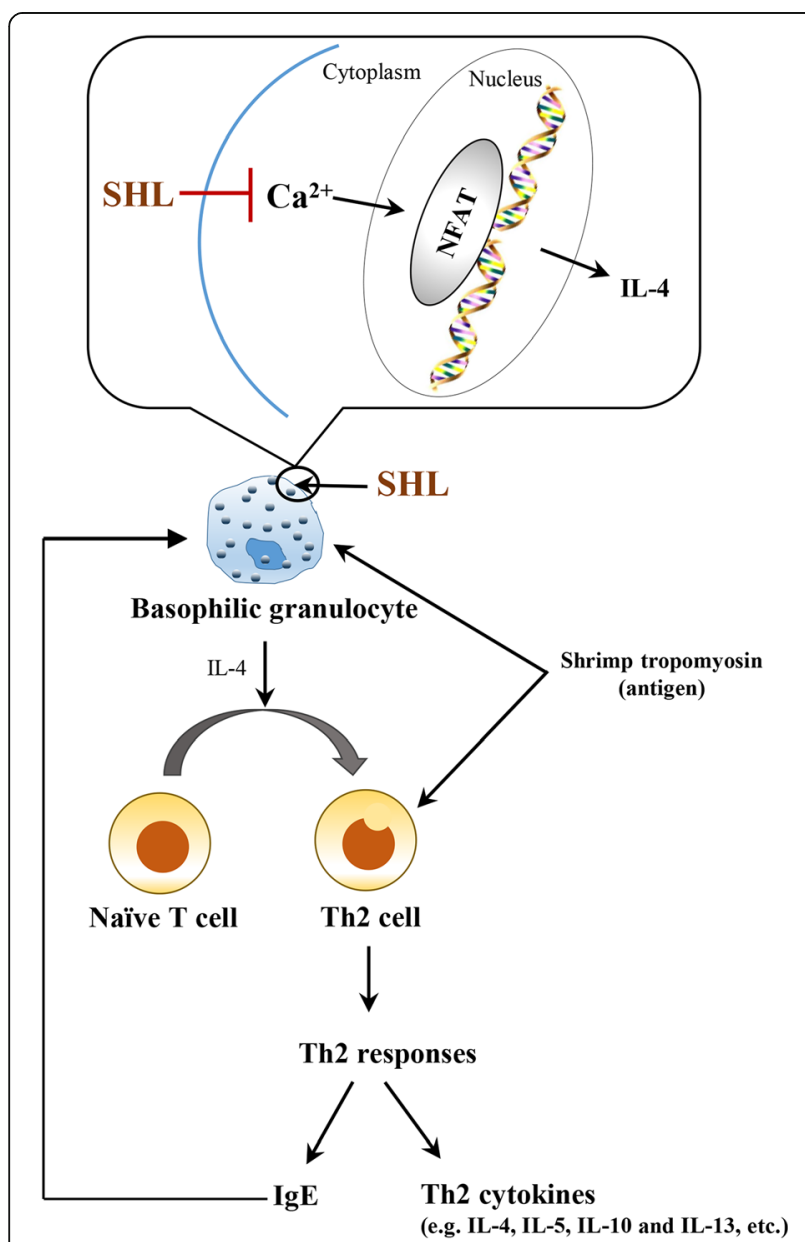

Fig. 4 Schematic diagram depicting how SHL reduces ST-induced Th2 immunity lowers $\mathrm{BG} \mathrm{Ca}_{[\mathrm{c}]}^{2+}$ levels to inhibit NFAT nuclear translocation. Indeed, SHL markedly prevented the STinduced $\mathrm{Ca}_{[c]}^{2+}$ elevation in the anti-ST IgE-sensitized RBL-2H3 cells (Fig. 3f and Additional file 5: Table S3).

\section{Conclusions}

In summary, our findings reveal, for the first time, that SHL attenuates ST-induced Th2-cytokines release (e.g. IL-4, IL5, IL-10 and IL-13) and serum sIgE production. This suppressive effect of SHL on Th2 immunity is attributed to its inhibition of BG activation, including suppressing CD200R surface expression and decreasing IL-4 production, in the early or middle/late stage. The latter mechanism probably involves in lowering $\mathrm{Ca}_{[\mathrm{c}]}^{2+}$ levels and then suppressing dephosphorylation of NFAT (Fig. 4). Our observations provide a pharmacological basis for the clinical use of SHL to relieve type I hypersensitivity by a successive dose regimen.

\section{Additional files}

Additional file 1: Figure $\mathbf{S 1}$. Schedule for the preparation of the ST-sensitized mice. (DOCX $115 \mathrm{~kb}$ )

Additional file 2: Figure S2. Proportion of basophils in the splenocytes separated by a MACS system using a FACSCalibur flow cytometer. (DOCX 174 kb)

Additional file 3: Table S1. Raw data for Fig. 1. (DOCX 18 kb)

Additional file 4: Table S2. Raw data for Fig. 2. (DOCX 18 kb)

Additional file 5: Table S3. Raw data for Fig. 3. (DOCX 21 kb)

Additional file 6: Figure S3. Effect of SHL on the viability of basophil-rich splenocytes. The cells were treated with $\mathrm{SHL}$ at the indicated concentrations for $24 \mathrm{~h}$. Cell viability was assessed using an MTS assay. (DOCX 84 kb)

\section{Abbreviations}

APC: Antigen-presenting cell; BG: Basophilic granulocyte; $\mathrm{Ca}_{[\mathrm{c}]}^{2+}$ : Cytosolic $\mathrm{Ca}^{2+}$. DCs: Dendritic cells; LNs: Lymph nodes; mAb: Monoclonal antibody; NCT: Naïve CD4+ T; NFAT: Nuclear factor of activated T cells; OD: Optical density; SHL: Shuang-Huang-Lian; slgE: Specific IgE; slgG: Specific IgG; ST: Shrimp tropomyosin; Th: T-helper; TlgE: Total IgE

\section{Funding}

This work was supported by CAMS Innovation Fund for Medical Sciences (CIFMS) (2016-I2M-3-015), National S \& T Major Project and Scientific Researchers Aiding Enterprise Item from the Ministry of Science and Technology of the People's Republic of China (Nos. 2014ZX09201022-006 and 2015ZX09501004-001-003), and National Natural Science Foundation of China (Nos. 81601385 and 81274163).

\section{Availability of data and materials}

The datasets supporting the conclusions of this article are included within the article and its additional files (Additional file 3-5: Tables S1-S3).

\section{Authors' contributions}

$F Q, H Y, H R$ and $G Y$ performed the main experiments. $F Q$ wrote the manuscript. $F Q$ and $Q R$ revised the manuscript. FL and $Q R$ performed some biological experiments. CR analyzed the data. QY designed the study. All authors read and approved the final manuscript.

\section{Ethics approval}

All the animal experiments were carried out according to the National Institutes of Health Guide for Care and Use of Laboratory Animals and approved by the Animals Ethics Committee of the IMPLAD of Chinese Academy of Medical Sciences. 


\section{Consent for publication}

Not applicable.

\section{Competing interests}

The authors declare that they have no competing interests.

\section{Publisher's Note}

Springer Nature remains neutral with regard to jurisdictional claims in published maps and institutional affiliations.

Received: 11 September 2017 Accepted: 22 December 2017 Published online: 03 January 2018

\section{References}

1. Oh H, Ghosh S. NF-KB: roles and regulation in different CD4 (+) T-cell subsets. Immunol Rev. 2013;252:41-51.

2. HÄGGQVIST B, HULTMAN P. Effects of deviating the Th2-response in murine mercury-induced autoimmunity towards a Th1-response. Clin Exp Immunol. 2003;134:202-9.

3. Maggi E, Parronchi P, Manetti R, Simonelli C, Piccinni MP, Rugiu FS, De Carli $M$, Ricci M, Romagnani S. Reciprocal regulatory effects of IFN-gamma and IL-4 on the in vitro development of human Th1 and Th2 clones. J Immunol. 1992;148:2142-7.

4. Na H, Cho M, Chung Y. Regulation of Th2 cell immunity by dendritic cells. Immune Netw. 2016:16:1-12.

5. Rogge L, Barberis-Maino L, Biffi M, Passini N, Presky DH, Gubler U, Sinigaglia F. Selective expression of an interleukin-12 receptor component by human Thelper 1 cells. J Exp Med. 1997;185:825-31.

6. Nakanishi K. Basophils are potent antigen-presenting cells that selectively induce Th2 cells. Eur J Immunol. 2010:40:1836-42.

7. Otsuka A, Nakajima S, Kubo M, Egawa G, Honda T, Kitoh A, Nomura T, Hanakawa S, Sagita-Moniaga C, Kim B, Matsuoka S, Watanabe T, Miyachi Y, Kabashima K. Basophils are required for the induction of Th2 immunity to haptens and peptide antigens. Nat Commun. 2013;4:1739.

8. Perrigoue JG, Saenz SA, Siracusa MC, Allenspach EJ, Taylor BC, Giacomin PR, Nair MG, Du Y, Zaph C, van Rooijen N, Comeau MR, Pearce EJ, Laufer TM, Artis D. MHC class II-dependent basophil-CD4 ${ }^{+} \mathrm{T}$ cell interactions promote T (H) 2 cytokine-dependent immunity. Nat Immunol. 2009;10:697-705.

9. Sokol CL, Chu NQ, Yu S, Nish SA, Laufer TM, Medzhitov R. Basophils function as antigen-presenting cells for an allergen-induced T helper type 2 response. Nat Immunol. 2009;10:713-20.

10. Yoshimoto T, Yasuda K, Tanaka H, Nakahira M, Imai Y, Fujimori Y, Nakanishi K. Basophils contribute to $T(\mathrm{H})$ 2-lgE responses in vivo via IL-4 production and presentation of peptide-MHC class II complexes to CD4+ T cells. Nat Immunol. 2009:10:706-12.

11. Sokol CL, Barton GM, Farr AG, Medzhitov R. A mechanism for the initiation of allergen-induced T helper type 2 responses. Nat Immunol. 2008:9:310-8.

12. Wynn TA. Basophils trump dendritic cells as APCs for $T(H) 2$ responses. Nat Immunol. 2009:10:679-81.

13. State Pharmacopoeia Committee. Chinese pharmacopoeia (Vol. 1). Beijing: Chemical Industry Press; 2010. p. 846-8.

14. Fang L, Gao Y, Liu F, Hou R, Cai RL, Qi Y. Shuang-huang-lian attenuates lipopolysaccharide-induced acute lung injury in mice involving antiinflammatory and antioxidative activities. Evid Based Complement Alternat Med. 2015;2015:283939.

15. Gao Y, Fang L, Cai R, Zong C, Chen X, Lu J, Qi Y. Shuang-Huang-Lian exerts anti-inflammatory and anti-oxidative activities in lipopolysaccharidestimulated murine alveolar macrophages. Phytomedicine. 2014;21:461-9.

16. Gao Y, Hou R, Fei Q, Fang L, Han Y, Cai R, Peng C, Qi Y. The three-herb formula Shuang-Huang-Lian stabilizes mast cells through activation of mitochondrial calcium uniporter. Sci Rep. 2017;7:38736.

17. Chen HS, Huang QM. Shuang-Huang-Lian powder-injection for the treatment of bronchial asthma (30 cases). Guangxi J Tradit Chin Med. 1998;21:16.

18. Dong $\mathrm{YH}$, Sun ZY, Chu AH. Clinical analysis of the adjuvant therapy of Shuang Huang Lian on infantile asthma through aerosol inhalation (54 cases). J Conval Rehab. 1997;12:1997.

19. Li XM, Schofield BH, Huang CK, Kleiner Gl, Sampson HA. A murine model of IgE-mediated cow's milk hypersensitivity. J Allergy Clin Immunol. 1999;103:206-14.
20. Abril-Gil M, Massot-Cladera M, Pérez-Cano FJ, Castellote C, Franch A, Castell M. A diet enriched with cocoa prevents IgE synthesis in a rat allergy model. Pharmacol Res. 2012;65:603-8.

21. Banerjee S, Medina-Fatimi A, Nichols R, Tendler D, Michetti M, Simon J, Kelly CP, Monath TP, Michetti P. Safety and efficacy of low dose Escherichia Coli enterotoxin adjuvant for urease based oral immunisation against helicobacter pylori in healthy volunteers. Gut. 2002;51:634-40.

22. Torrero MN, Larson D, Hübner MP, Mitre E. CD200R surface expression as a marker of murine basophil activation. Clin Exp Allergy. 2009;39:361-9.

23. Putney JW. Calcium signaling: deciphering the calcium-NFAT pathway. Curr Biol. 2012;22:R87-9.

24. Li F, Li HQ. The study of Lonicera extract from water solution on ovalbumin -induced allergic mice model. J Chongqing Med Univ. 2004;29:288-91.

25. Shin HS, Bae MJ, Jung SY, Shon DH. Preventive effects of skullcap (Scutellaria Baicalensis) extract in a mouse model of food allergy. J Ethnopharmacol. 2014;153:667-73.

26. Sung $Y Y$, Lee AY, Kim HK. Forsythia Suspensa fruit extracts and the constituent matairesinol confer anti-allergic effects in an allergic dermatitis mouse model. J Ethnopharmacol. 2016;187:49-56.

27. Shin HS, Bae MJ, Choi DW, Shon DH. Skullcap (Scutellaria Baicalensis) extract and its active compound, wogonin, inhibit ovalbumin-induced Th2mediated response. Molecules. 2014;19:2536-45.

28. Zhu J, Paul WE. Peripheral CD4+ T-cell differentiation regulated by networks of cytokines and transcription factors. Immunol Rev. 2010;238:247-62.

29. Oetjen LK, Noti M, Kim BS. New insights into basophil heterogeneity. Semin Immunopathol. 2016:38:549-61.

30. Tsujimura Y, Obata K, Mukai K, Shindou H, Yoshida M, Nishikado H, Kawano Y, Minegishi Y, Shimizu T, Karasuyama H. Basophils play a pivotal role in immunoglobulin-G-mediated but not immunoglobulin-E-mediated systemic anaphylaxis. Immunity. 2008;28:581-9.

\section{Submit your next manuscript to BioMed Central and we will help you at every step:}

- We accept pre-submission inquiries

- Our selector tool helps you to find the most relevant journal

- We provide round the clock customer support

- Convenient online submission

- Thorough peer review

- Inclusion in PubMed and all major indexing services

- Maximum visibility for your research

Submit your manuscript at www.biomedcentral.com/submit
) Biomed Central 